\title{
Modelling the Water Isotope Signal in the Quaternary
}

\section{GeoRg HoffmanN}

Laboratoire des Sciences du Climat et de I'Environnement, DSM, Orme des Merisiers, Bâtiment 703, C.E. Saclay, 91191 Gif-sur-Yvette, FRANCE; hoffmann@Isce.saclay.cea.fr

Water isotopic signals from paleo archives represent multiparameterdependent climate records. Past changes in various quantities and processes may have affected the isotopic compositions of atmospheric moisture and precipitation. Even a detailed regional calibration study striving to understand all factors controlling the water isotopes on a seasonal to inter-annual basis cannot take into account the entire variety of possible changes in the past, ranging from circulation changes and corresponding changes in the distribution of source regions to changes of the local hydrological cycle (e.g., lakes, vegetation type and coverage), variations in the seasonality of the precipitation, etc.

General Circulation Models (GCMs) with an embedded isotope module allowing the prognostic computation of the water isotopes provide an effective means of testing the influence of a certain number of these different factors (Joussaume et al., 1984; Jouzel et al., 1987; Hoffmann et al., 1998; Werner et al., 2000). In an ongoing study, for example, a set of numerical simulations has been performed with

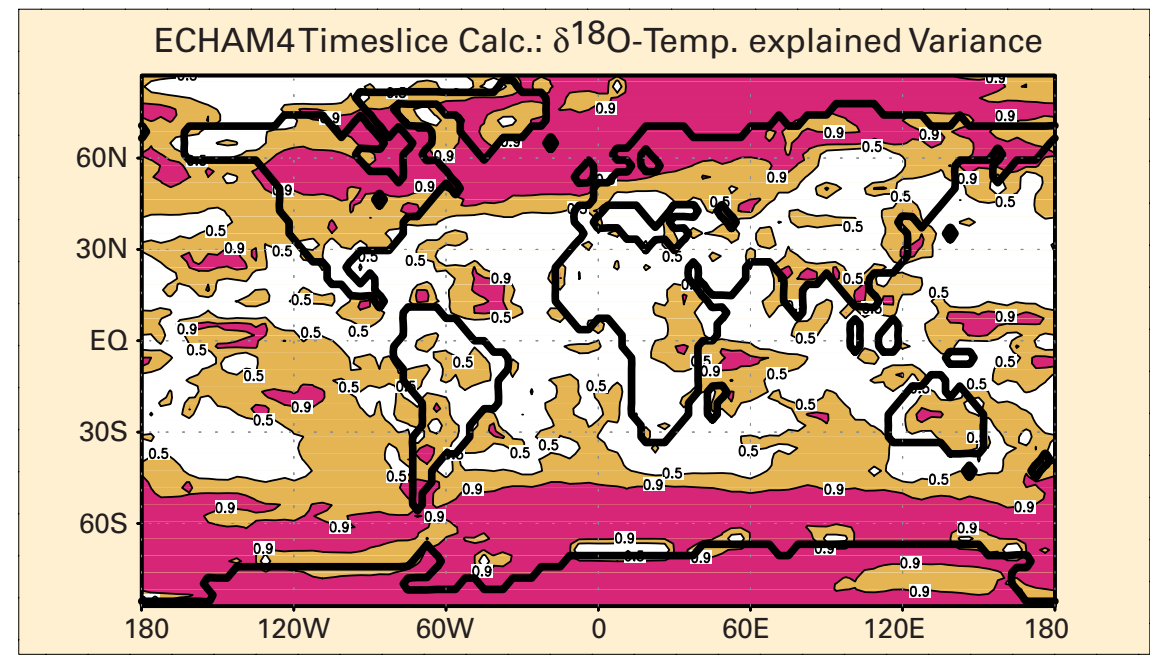

Fig. 1: Temporal correlation $(=r)$ between the isotope and temperature anomalies calculated for each point of the ECHAM4 grid for the Holocene time-slice calculations. As expected, the explained variance $\left(=r^{2}\right)$ of the isotope signal is characterised by a strong contrast between high and low latitudes.

tions traditionally originates from their role as a proxy for local temperatures, particularly at high latitudes. Therefore the first question the present study addresses is to what extent the regional $\delta^{18} \mathrm{O}$ or $\delta \mathrm{D}$ signal is controlled by local temperature variations. Figure 1 shows the explained variance $\left(r^{2}\right.$ in a simple correlation approach) computed for the simulated water isotope signal and the corresponding temperatures. As expected, there is a distinct high- versus low-

Table 1: Boundary conditions for the six paleosimulations used in this study

\begin{tabular}{|llclll|}
\hline Time Slice & $\mathbf{C O}_{\mathbf{2}}$ & Insolation & SST & Sea Level & $\delta_{\text {Ocean }}$ \\
\hline $6 \mathrm{kyr} \mathrm{BP}$ & $280 \mathrm{ppm}$ & $6 \mathrm{kyr} \mathrm{BP}$ & Modern & Control & $0 \%$ \\
$11 \mathrm{kyr} \mathrm{BP}$ & $280 \mathrm{ppm}$ & $11 \mathrm{kyr} \mathrm{BP}$ & Interpol. CLIMAP & -30 Meters & $+0.4 \%$ \\
$14 \mathrm{kyr} \mathrm{BP}$ & $240 \mathrm{ppm}$ & $14 \mathrm{kyr} \mathrm{BP}$ & Interpol. CLIMAP & -60 Meters & $+0.8 \%$ \\
$16 \mathrm{kyr} \mathrm{BP}$ & $220 \mathrm{ppm}$ & $16 \mathrm{kyr} \mathrm{BP}$ & Interpol. CLIMAP & -87 Meters & $+1.2 \%$ \\
$21 \mathrm{kyr} \mathrm{BP}$ & $200 \mathrm{ppm}$ & $21 \mathrm{kyr} \mathrm{BP}$ & CLIMAP & -106 Meters & $+1.5 \%$ \\
$175 \mathrm{kyr} \mathrm{BP}$ & $200 \mathrm{ppm}$ & $175 \mathrm{kyr} \mathrm{BP}$ & CLIMAP & -106 Meters & $+1.5 \%$ \\
\hline
\end{tabular}

the ECHAM4 climate model of the Max-Planck Institut für Meteorologie, Hamburg, aiming to realistically reproduce six paleo time-slices of global climate 6 kyr BP, 11 kyr BP, 14 kyr BP, 16 kyr BP, 21 kyr BP, 175 kyr BP), plus "modern" and "preindustrial". Boundary conditions for the paleo time-slice calculations are listed in Table 1.

Though various factors control the isotopic composition of precipitation, the importance of the water isotopes in paleoclimate investiga- latitude pattern. In high northern or southern latitudes the water isotope signal is largely controlled by corresponding local temperature variation, in many areas more than $90 \%$. In contrast, at low latitudes (approximately $<45^{\circ} \mathrm{N}$ and S) the simulated isotope pattern is generally more strongly affected by precipitation intensity and circulation changes (though noting that temperature sensitivity does occur in some low-latitude locations because of convective precipitation triggered by temperature changes).

A key factor potentially biasing the interpretation of the water isotopes as a paleothermometer, even at high latitudes, is the seasonality of precipitation. Any change in the seasonal distribution of precipitation naturally shifts the annual mean water isotopic signal versus the corresponding seasons. The common assumption that the local spatial isotope-temperature gradient is a valid approximation of the temporal gradient (modern analogue approach) crucially depends on unchanged and approximately equally distributed seasonality. Figure 2 demonstrates the importance of this feature, focussing on the simulated seasonality of temperature, precipitation and water isotopes over central Greenland. In this region the simulated spatial $\delta^{18} \mathrm{O}-\mathrm{MAT}$ gradient under modern conditions is of the order $0.5 \% /{ }^{\circ} \mathrm{C}$, slightly lower than that observed. Whereas temperature and water isotopes are characterized by a strong but essentially unchanged seasonal cycle throughout the entire period, precipitation amount and seasonality are dramatically different under glacial and non-glacial conditions. Under non-glacial climate conditions, precipitation is 


\section{Science Highlights}

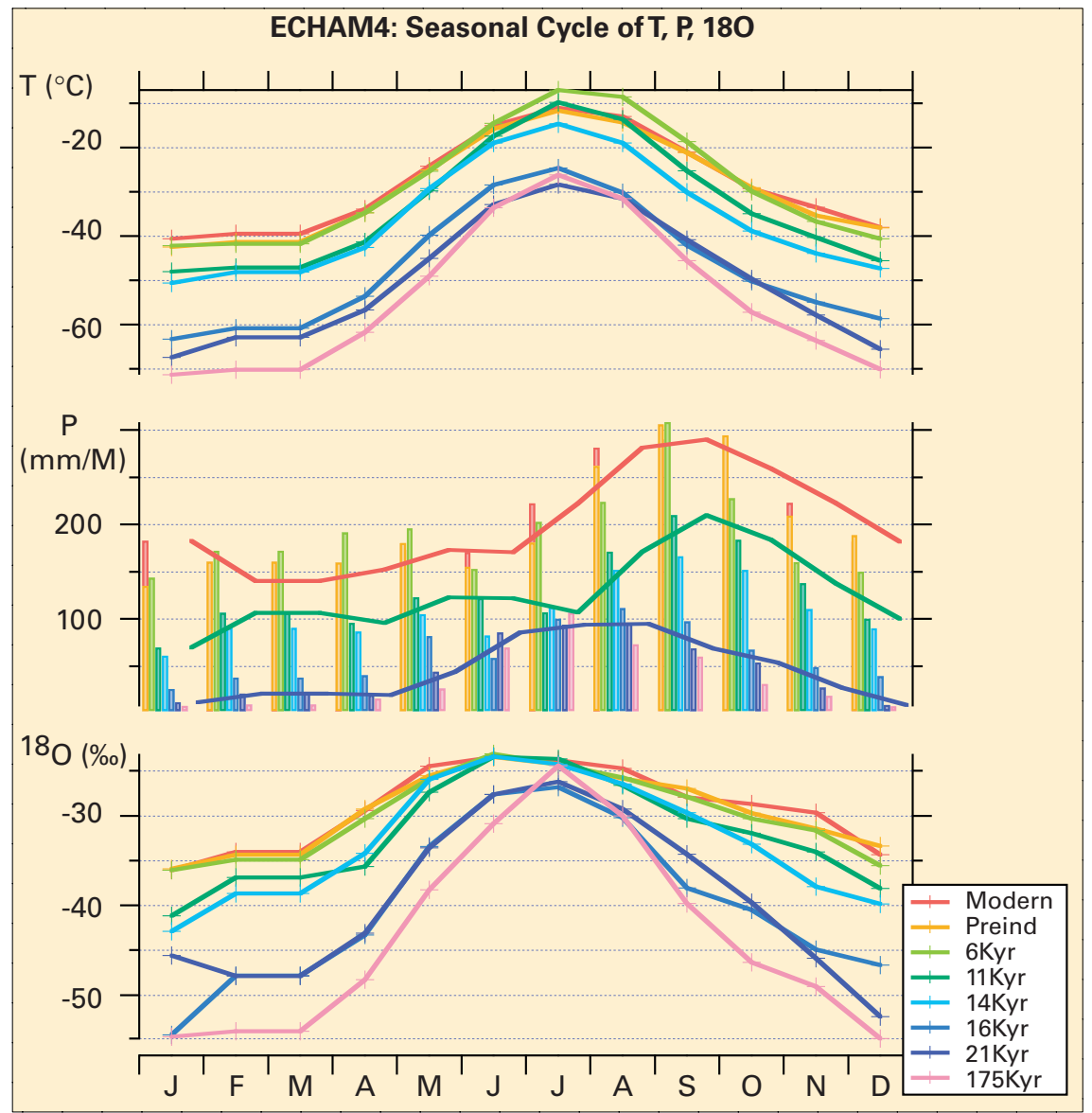

Fig. 2: Simulated (ECHAM4) seasonality of temperature, precipitation and $\delta^{18} \mathrm{O}$ over Central Greenland. Between $11 \mathrm{kyr} B P$ and $14 \mathrm{kyr} B P$ there is a pronounced reduction of winter precipitation, which is responsible for the strong bias of the isotope paleothermometer to warmer summer temperatures during near-and full-glacial conditions.

fairly equally distributed over the year, with a slight maximum in early autumn. A contrasting situation exists under near- or full-glacial conditions, marked by reduced precipitation overall, and most particularly during winter, thus strong- ly biasing the water isotope signal towards that of the summer. This mechanism explains about $70 \%$ of the difference between the simulated spatial and temporal isotopetemperature gradients - the latter being unreasonably low (in the or- der of $0.2 \% \circ /{ }^{\circ} \mathrm{C}$ ) in the absence of correction for seasonality, which increases the gradient to about $0.4 \%{ }^{\circ} \mathrm{C}$. This provides a graphic example of the utility of isotopicGCMs as "thinking tools", since this profound shift in the temporal isotope-temperature relation can be related directly to the extreme southward shift of the winter polar front under glacial conditions and the concomitant suppression of meridional moisture transport to central Greenland, thus offering a clear mechanistic explanation for the apparent failure of the isotope paleothermometer across the glacial-interglacial transition (e.g., see Cuffey et al., 1995; Dahl-Jensen et al., 1998; Severinghaus et al., 1998; Lang et al., 1999).

\section{REFERENCES}

Cuffey, K.M., Clow, G.D., Alley, R.B., Stuiver, M., Washington, E.D. and Saltus, R.W., 1995: Large Arctic temperature change at the Glacial-Holocene transition. Science 270: 455-458.

Dahl-Jensen, D., Mosegaard, K., Gundestrup, N. Clow, G.D., Johnsen, S.J., Hansen, A.W. and Balling, N., 1998: Past temperatures directly from Greenland Ice Sheet. Science 282: 271-281.

Hoffmann, G., Werner, M. and Heimann, M., 1998: The water isotope module of the ECHAM atmospheric general circulation model - A study on time scales from days to several years, Journal of Geophysical Research 103: 16,871-16,896.

Joussaume, J., Sadourny, R. and Jouzel, J., 1984: A general circulation model of water isotope cycles in the atmosphere. Nature 311: 24-29.

For full references please consult:

www.pages-igbp.org/products/newsletters/ref2002_2.htm

\section{Towards a Regional Synthesis of Mediterranean Climatic Change Using Lake Stable Isotope Records}

\section{Neil Roberts and Matt Jones}

ISOMED working group, Quaternary Environments Research Group, Department of Geographical Sciences, University of Plymouth, UK; cnroberts@plymouth.ac.uk; m.jones-4@plymouth.ac.uk.

The Mediterranean basin is a climate-sensitive region with an exceptionally long and rich history of human use and abuse, stretching back to the advent of Neolithic farming in Southwest Asia around $10 \mathrm{kyr}$ ago. These factors have led to a great interest in the environmental history of the region, especially through the last glacial-interglacial transition and the Holocene. However, the long and complex history of cultural-envi- ronmental relations has created some difficulties in distinguishing climate change from human impact in many palaeoenvironmental proxy records, for example through pollen analysis .

Unlike pollen, isotope-based records from non-marine settings are unlikely to be compromised by human impact, and a substantial volume of work from continental archives from the region is now appearing in the literature, in par- ticular from lake records (Fig. 1). This number of isotope records has the potential to allow comparison of environmental change across the Mediterranean basin. However, which specific climatic and environmental factors drive the changes in stable isotope ratios - as measured from various biogenic and authigenic fractions of lake sediment - remains under debate. 